\title{
THE DEVELOPMENT OF GEOSPATIAL EDUCATION AND TRAINING IN NORTH AFRICA
}

\author{
Ian Dowman ${ }^{\mathrm{a}}$ and Kamal Labbassi ${ }^{\mathrm{b}}$
}

\begin{abstract}
${ }^{a}$ Dept. of Civil, Environmental and Geomatic Engineering, University College London, Gower Street, London, WC1E 6BT UK. i.dowman@ucl.ac.uk

${ }^{b}$ Dept of Geology, Chouaib Doukkali University, B.P: 20, El Jadida, Morocco. labbassi@ucd.ac.ma
\end{abstract}

\section{Commission VI, WG VI/3}

KEY WORDS: Curriculum, geospatial, North Africa

\begin{abstract}
:
This paper described the progress in a project funded by the ISPRS Scientific Initiative to develop a curriculum for the African Geospatial Sciences Institute (AGSI) in Tunis. AGSI is a non profit organisation registered in Germany and has the objective of developing geospatial capacity in North Africa through training, education and the provision of facilities. The first step in the project involved a survey of potential stakeholders in North Africa in order to determine the requirements for training and education. The questionnaire sought information on the type of work which organisations in North Africa undertake, and the type of employees who are needed to fill gaps in the skill set required. It also solicited information on the type of training which is needed and the level of qualification required. The results from this questionnaire are analysed in the paper which also reports on the discussion with stakeholders at a workshop held in Tunis in March 2014, which also resulted in a draft curriculum.
\end{abstract}

\section{INTRODUCTION}

The International Society for Photogrammetry and Remote Sensing (ISPRS) has provided some funding to develop a curriculum for The African Geospatial Sciences Institute (AGSI) in Tunis. The African Geospatial Sciences Institute is a non-profit organisation registered in Germany which is supported by industry, government and academia. The objective of AGSI is to accelerate the geospatial capacity development in North Africa by providing the facilities for geospatial projects and management training to regional government employees, university graduates, private individuals and companies. The initial curriculum will concentrate on vocational geospatial training, emphasizing practical, project-based work. Learningby-doing is the priority and whilst all participants will be encouraged to continue with a more formal education, there will also be support for anyone who wants to start his own business. The curriculum will take account of the resources available and particularly look at how low cost equipment such as UAVs and low cost or open source software can be used. The emphasis will be on training and education which is fit for purpose in the region and which will allow those completing the course to work efficiently and effectively. Teaching will be mostly in English although some courses may be provided in French or Arabic.

\section{AIMS AND OBJECTIVES}

The primary objective of this project is to support capacity building in North Africa. North Africa has been subject to severe disruption in recent years and there is an urgent need for the construction of infrastructure (Oeldenberger and Khaled, 2012) and for the services of trained geospatial professionals and technicians. AGSI depends on donations for its income and for time given by supporting organisations and individuals. The objective of AGSI is to accelerate the geospatial capacity development in North Africa by providing the facilities for geospatial projects and management training to regional government employees, university graduates, private individuals and companies.

Funds from the ISPRS Scientific Initiative have been used to develop a curriculum for AGSI based on the requirements of the region and using the expertise of ISPRS working groups.

The project has involved a survey of potential stakeholders in North Africa and the drafting of a curriculum on the basis of the returns from the survey. The results of the questionnaire and the draft curriculum were discussed at a workshop held in Tunis in March.

AGSI will initially concentrate on vocational geospatial training, emphasizing practical, project-based work. Learningby-doing is the priority and whilst all participants will be encouraged to continue with a more formal education, there will also be support for anyone who wants to start his own business.

A new institution like AGSI needs a well founded structure from the outset and the expertise in ISPRS working groups has been used to provide such as structure. In order to establish the required structure a combination of local information and international expertise is needed.

\section{PARTICIPANTS}

The proposal to the Science Initiative was prepared by Ian Dowman with support from WG VI/3 and a team with experience in education in North Africa:

Tsehaie Woldai, Vice President, Commission VI

Henny Mills, Co-chair WG VI/3.

Jide Kufoniyi, President, AARSE. 
Bola Ayeni, Head of GIS, RECTAS, Nigeria.

Hussein Farah, Director General, RCMRD, Kenya.

Riadh Abdelfattah, Associate Professor, University of Carthage, Higher School of Communications of Tunis (SUPCOM).

Kamal Labbassi, Department of Geology, University of El Jadida, Morocco.

Support has also come from The German GeoConsultants Group (3G) which is organising the 2014 Geospatial Conference Tunisia and Dieter Fritsch, Institute for Photogrammetry (IfP), University of Stuttgart and the German University in Cairo (GUC), Other organisations, including ICA and CRTEAN are also supporting the project.

Kamal Labbassi, Department of Geology, University of El Jadida, Morocco. Is the administrator for the project.

\section{DETAILS OF PROJECT}

\subsection{Prepare and distribute questionnaire}

The survey was designed to determine the training requirements in North Africa. The questionnaire was prepared in consultation with the project team. The main questions are:

1. Information about your organization.

Name of organization/company

Nature of the organization

Name of contact

Full Address (including phone, fax and email)

Official Website

Number of employees

Type of activity (check as many as relevant)

Role of geospatial information within the organisation

(limit 50 words

Main techniques used

Geographic area of business

Principal equipment used

Principal software used

Specify your needs for training in the field of Geospatial Information? (Indicate the areas in order of importance in the company)

\section{Staff requirements}

What type of staff do you require? Please complete the table in order of priority of topic

Are you willing to release staff to attend courses at AGSI? Yes/No

If yes what type of training is most convenient? Full time; Day release; Evening; Other.

Type of training: In your opinion how should this training be conducted?

3. Example of large projects

(List the regular work of the institution, indicating where appropriate on behalf of which organization they were made (beneficiary))

4. Support in terms of equipment and teaching personnel are you able to help AGSI through provision of equipment, software or personnel?

5. Do you have any software packages available for use at AGSI? If so please list
6. Do you have any staff to deliver training at AGSI? If so please list

7. Please add any additional comments

8. Can the information provided be published? Yes/No

The distribution list was compiled with help from The German GeoConsultants Group (3G) which organized the Geospatial Conference in Tunis (GCT) in 2012 and 2013 who have a comprehensive contact list for North Africa.

\subsection{Analysis of Questionnaire}

4.2.1 Introduction.

The questionnaire was prepared and sent to a large number of organizations in North Africa to determine the requirements for training and education of potential stakeholders in the region.

4.2.2 Nature of the organisations.

By the time of the workshop in Tunis 17 responses had been received: 10 from Tunisia, 3 from Morocco, 2 from Mauritania, 1 from Gabon and 1 from Nigeria. This was a disappointing responses and a request will be sent for more responses. The majority of organizations responding are public (68.75\%). However, we received more responses from the private sector in Tunisia (40\%). Most of the organizations (62.5\%) are large, with over 100 employees and their fields of activity are variable and include: telecommunications, water, forest and agriculture, cartography and civil engineering. More than half of organizations $(56.25 \%)$ work in their own country whilst $8.75 \%$ work at Regional level and at local level; $6.25 \%$ did not specify their Geographic area of business.

\subsubsection{Requirements.}

$31.81 \%$ of the organizations were unable to specify their needs in terms of staff. $27.27 \%$ will need qualified personnel in Photogrammetry and Remote Sensing and $22.72 \%$ need expertise GIS. Other requirements are shared between cartography, laser scanning and GNSS with a percentage of $4.54 \%$ each.

In terms of topics, the most requested needs were split between Photogrammetry/Remote Sensing and GIS with percentages respectively $26.82 \%$ and $24.39 \%$. Other needs were between laser scanning, survey equipment, GNSS and UAVs with percentages of $7.3 \%$ to $9.75 \%$.

On training, all organizations are willing to release staff to attend courses at AGSI. The most convenient training is day release at $40 \%$, followed by full time with $33.3 \%$. The type of training most desired is face to face courses and through conferences, seminars and workshops with $29.62 \%$, followed by tailor-made courses with $25.92 \%$. Other organizations have preferred distance courses and short stay courses at $7.4 \%$ each.

In summary although the questionnaires could not be considered as a good statistical sample, they did show the need for training in geospatial science, particularly in photogrammetry, remote sensing and GIS. Day release was the preferred mode of teaching and there is a willingness on the part of employers to support the aims of AGSI. These results were discussed at the workshop and further returns will be incorporated in the final report. 


\subsection{Workshop}

The workshop to discuss the results of the questionnaire and draft a curriculum for AGSI was held on 17th March 2014 in Tunis. Around 25 people attended, most from Tunisia and Libya representing a range of organisations, but including many from government departments and private companies. The workshop started with presentations on the ISPRS project and on AGSI, and outlined the progress made to date. After a presentation on the analysis of the questionnaire a discussion covered many of the issues raised in establishing AGSI and defining its role.

Two main conclusions could be drawn from the returns of the questionnaire: first from the low number of returns it could be inferred that there is not a great deal of interest in a using geospatial data in projects in North Africa; and second that those who did answer the questionnaire were unclear on what it could do for them ( $32 \%$ did not specify requirements). It was clear from this and from comments from the workshop participants that the first priority was to increase understanding of the value of geospatial data amongst decision makers, those commissioning work and those undertaking it.

In designing a curriculum based on the principles set out above there are going to be a number of constraints. This issue was discussed at the workshop.

1. Availability of equipment and software.

It was established that the priorities for equipment are a UAV, a RTK base station, GNSS rovers, and hand held GIS and GNSS data collection units. A range of software should be available including photogrammetric suites and GIS packages from a number of vendors. Open source software should be used to supplement commercial packages. It will be necessary to consider scenarios for teaching with limited equipment

2. Staff

The availability of staff is a major factor in what can be taught. Ideally people with a range of expertise could be employed but this can be supplemented with teachers employed by companies in the region or from elsewhere. One possible scenario is to use international lecturers with support from local demonstrators or trainers, the local people would ensure continuity of support. It was noted that many experts in Tunisian universities are not satisfied because they are not using their full potential, these people could be used by AGSI.

3. Local requirements.

These have been obtained from the questionnaire responses. One particular aspect to be considered is the type of delivery, this could be full time, day release or evening sessions. Courses could take place at the AGSI premises or at the offices of those requiring training.

4. Regional approaches

There is a need to look at what courses exist and for AGSI to be complementary to these and to learn lessors from them. Opportunities for collaboration should be explored.

5. Legal issues

It was established that there were no legal implications to AGSI, but training should incorporate information on the tendering process in the country and the uncertainty which may surround bidding.

Initially the main role of AGSI should be to create an understanding of the value of geospatial data and the processes involved in processing the data and generating information. It is necessary to give the basics behind software, not enough just to train in use of software. People need to know what to capture and how to capture it. Data integration is also important

It was proposed that a progressive series of courses be adopted so that the first courses are aimed at people who could champion the use of geospatial data within their organisations and emphasise the benefits and value if geospatial data to provide information and increase efficiency (saving cost) within an organization. This should be followed by courses for managers who would implement the use of geospatial data, and finally courses for the people who will engage in data collection and use the software.

The competency model proposed by Careeronestop (2014) shows a full set of desirable skills as seen in figure 1, but AGSI needs to select those which are relevant to the local situation.

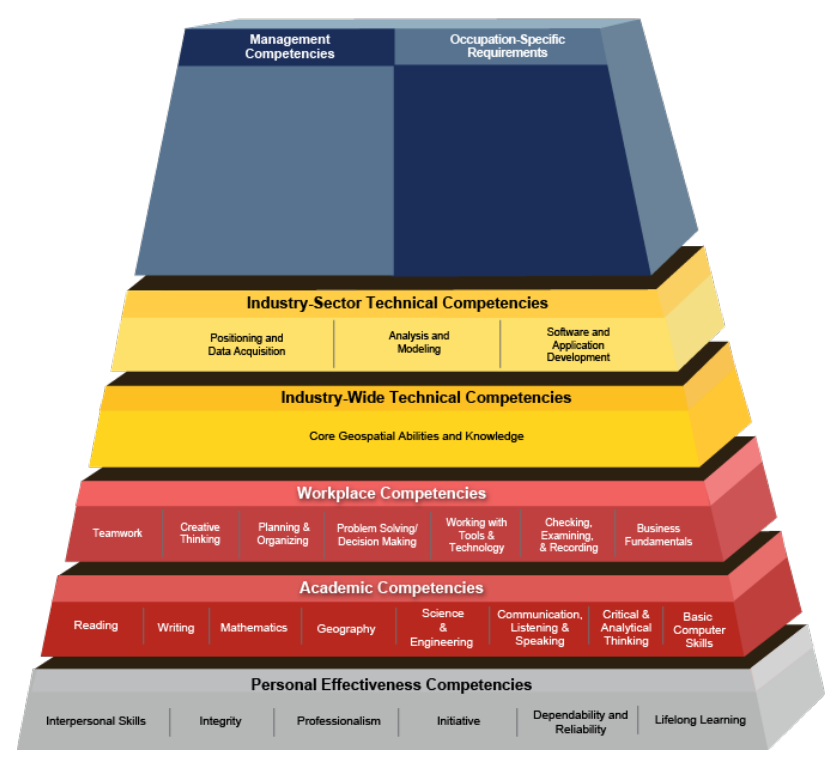

Figure 1. A competency model for Geospatial technology.

This progression proposed for AGSI is indicated in Figure 2.

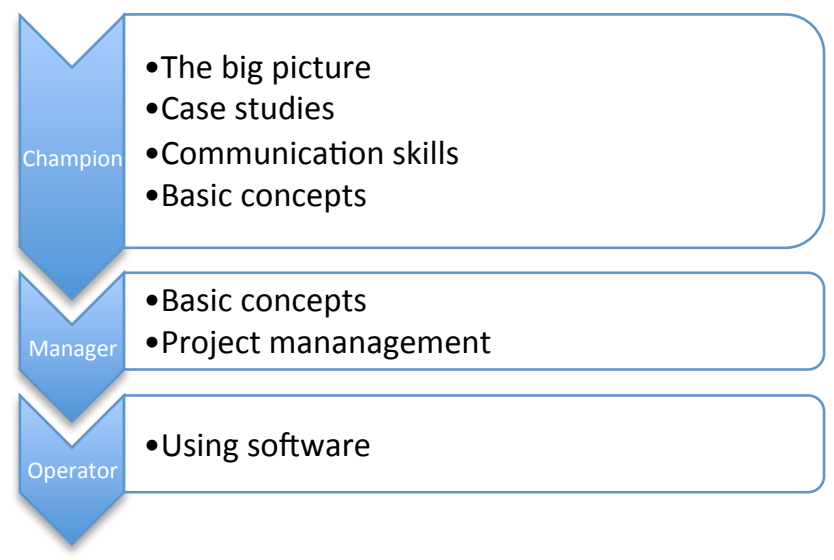

Figure 2. The progression of courses needed at AGSI.

Teaching should be developed on a modular basis and courses tailor made to fit various requirements. Table 1 has been developed to fit these principles and shows the modules proposed as a starting point. 


\begin{tabular}{|c|c|}
\hline Courses & Modules \\
\hline $\begin{array}{l}\text { An introduction to the use of } \\
\text { geospatial data }\end{array}$ & $\begin{array}{l}\text { The big picture } \\
\text { Case studies }\end{array}$ \\
\hline $\begin{array}{l}\text { Spatial data for decision } \\
\text { makers }\end{array}$ & $\begin{array}{l}\text { The role geospatial data in } \\
\text { projects } \\
\text { The value of Geospatial data } \\
\text { Case studies } \\
\text { Data quality }\end{array}$ \\
\hline Positioning systems & Positioning systems \\
\hline Workflows & Workflows \\
\hline Working with images & $\begin{array}{l}\text { Introduction to remote } \\
\text { sensing } \\
\text { Imaging sensors } \\
\text { Preprocessing image data } \\
\text { Characteristics of images } \\
\text { Geometric processes } \\
\text { (orthophotos and image } \\
\text { matching) } \\
\text { Data quality }\end{array}$ \\
\hline Image processing & Image processing \\
\hline Working with Lidar & $\begin{array}{l}\text { Positioning systems } \\
\text { Lidar }\end{array}$ \\
\hline Working with GIS & $\begin{array}{l}\text { GIS data structures } \\
\text { GIS data sources } \\
\text { GIS data analysis }\end{array}$ \\
\hline $\begin{array}{l}\text { Managing and presenting } \\
\text { image data }\end{array}$ & $\begin{array}{l}\text { Image processing } \\
\text { Visualisation }\end{array}$ \\
\hline $\begin{array}{l}\text { Thematic applications e.g. } \\
\text { Water } \\
\text { Forestry } \\
\text { Desertification and climate } \\
\text { change } \\
\text { Land administration } \\
\text { Marine and coastal } \\
\text { management } \\
\text { Urban management } \\
\text { Utilities } \\
\text { Renewable energy } \\
\text { infrastructure, } \\
\text { EIA } \\
\end{array}$ & $\begin{array}{l}\text { Modules relevant to the } \\
\text { application }\end{array}$ \\
\hline
\end{tabular}

Table 1. Basic courses with proposed modules.

These modules listed have not been normalised to be of equal weight and they clearly need to be defined in more detail. When defining the modules in detail it is suggested that where appropriate teaching should centre around projects which would involve practical work and demonstrate the end to end workflow of project.

Responses from the questionnaire and discussion at the workshop indicate that AGSI should start with short courses of $2-3$ weeks based on the modules set out above.

A number of other issues were discussed at the workshop.

\section{Collaboration}

There should be collaboration with local and regional colleges from the start and in the longer term there should be cooperation with European institutions, maybe delivering longer courses of 3-6 months. Student exchange could also take place for academic degrees.

\section{Certification}

Courses should be given recognition through certification. Ultimately they should achieve international certification. The European Credit Transfer Scheme (ECTS) could be used if this is possible, maybe jointly with a university (private) and/or industry. Government approval may be necessary. Issues of cross border education should be looked into.

\section{Promotion of geospatial data}

AGSI could also be instrumental in promoting geospatial data through grass roots effort in schools using portals such as digital-earth.eu. AGSI could also have a consultancy role to assist organisations to introduce geospatial data. Organisations should not expect to undertake projects on their own, but to look at how geospatial data can be used at all stages of a project, from planning, execution to analysis.

eLearning

The possibility of eLearning should be investigated. There are a number of courses available, both working towards degrees and short courses.

\subsection{Preparation of final curriculum}

The outcomes from the workshop and any further responses from the questionnaire will be incorporated into a new draft of the curriculum with details of the modules, which will be reviewed by the Project team and support team and presented in the final report.

\section{CONCLUSIONS}

\subsection{The curriculum}

The work completed to date has resulted in the project team having a acquired a good knowledge of the objectives and context of AGSI. A framework for the curriculum has been developed and a number of issues identified. Furthermore a draft set of modules have been identified and some detail added to these. Further work will be carried out on this.

\subsection{Lesson learned}

The process to date has demonstrated the value of having local knowledge and engaging with the beneficiaries of AGSI. The development of a full curriculum has been hampered by a poor response from the questionnaires, but this is in part due to the contracted time frame which was necessary because the workshop had to be held earlier than anticipated, allowing less time to collect and analyse responses. It is recommended that the time scale for similar projects in the future be long enough to collect all necessary background information before holding a workshop.

\subsection{General outcomes}

Apart from progress in the development a curriculum for the training of geospatial technicians in North Africa. ISPRS has benefitted from gaining experience in working in on a practical project and experiencing problems on the ground. ISPRS has gained exposure in the area and is open to further cooperation in the region. There has also been cooperation with ISPRS Regional Members and the potential to provide services to ISPRS members in the region

\subsection{Future work}

The questionnaire and the workshop have provided a good basis for developing a sound curriculum for AGSI. It is now 
necessary to refine the framework set out above and to add content in detail to the modules listed in Table 1. This will be done in the remaining time available to the project and a final report will be prepared.

\section{REFERENCES}

S. Oeldenberger and K. B. Khaled, 2012. The African Geospatial Sciences Institute (AGSI): A New Approach To Geospatial Training In North Africa. The International Archives of the Photogrammetry, Remote Sensing and Spatial
Information Sciences, Kyoto, Japan, Vol. XXXIX, Part B6, pp. 45-51.

Careeronestop (2014) Geospatial Technology Competency Model. http://www.careeronestop.org/competencymodel/ competency-models/geospatial-technology.aspx. March 2014

\section{ACKNOWLEDGEMENTS}

The AGSI curriculum project has been possible through a grant from the ISPRS Scientific Initiative. Support from the organisers of Geospatial Conference in Tunis 2014 is gratefully acknowledged. 